\title{
Burden and Quality of Life Among Primary Caregiver of Alcohol Dependence Syndrome
}

\author{
Bharat Kumar Goit $^{1,}$, , Bishnu Acharya ${ }^{2}$, Jai Bahadur Khattri $^{3}$, Rakhi Sharma ${ }^{1}$ \\ ${ }^{1}$ Department of Psychiatry, National Medical College, Birgunj, Parsa, Nepal \\ ${ }^{2}$ Sajha Hospital, Butwal, Rupandehi, Nepal \\ ${ }^{3}$ Department of Psychiatry, Manipal College of Medical College, Pokhara, Kaski, Nepal
}

Email address:

bharatgoit28@gmail.com (B. K. Goit)

${ }^{*}$ Corresponding author

To cite this article:

Bharat Kumar Goit, Bishnu Acharya, Jai Bahadur Khattri, Rakhi Sharma. Burden and Quality of Life Among Primary Caregiver of Alcohol Dependence Syndrome. American Journal of Psychiatry and Neuroscience. Vol. 9, No. 1, 2021, pp. 1-6. doi: 10.11648/j.ajpn.20210901.11

Received: December 18, 2020; Accepted: December 25, 2020; Published: January 12, 2021

\begin{abstract}
Background: Alcohol Dependence syndrome is one of the common psychiatric illnesses in the society. It not only affects the individual but also has major impact on the family members especially the primary caregiver. There are minimum studies regarding impact of the alcohol dependence patients on the primary caregiver in Nepal. The objective of this study was to study the burden and quality of life among primary caregiver of alcohol dependence syndrome. Material and Methods: This is a cross-sectional study conducted among the primary caregiver of alcohol dependent patient. This study is conducted in the in-patient and out-patient unit of Psychiatric Department of National Medical College and Teaching Hospital, Birgunj, Nepal. The total sample size was 123 taken by non-probability homogenous purposive sampling method. The diagnosis of alcohol dependence syndrome was made using International Classification of Disease-10 (ICD-10) criteria. The socio-demographic profile of alcohol dependence patients and their primary caregivers were assessed using semi-structured proforma. The burden and quality of life of the primary caregiver of the alcohol dependent patient were determined using Family Burden Interview Schedule (FBIS) and World Health Organization Quality of Life- BREF version. The data were entered and analyzed using SPSS 21. Result: In this study, it was found that caregiver of Alcohol Dependence Syndrome patient faced moderate to severe burden according to the different domains of Family Burden Interview Schedule. In quality of life assessment, the mean score on perception of quality of life was $2.78( \pm 0.66)$ and the mean score on overall perception of health was $3.57( \pm 0.64)$. Similarly, the mean score on physical health was $23.40( \pm 3.04)$, the mean score on psychological health was $18.91( \pm 2.36)$, the mean score on social relationships was $10.63( \pm 1.39)$, the mean score on the environment was $25.58( \pm 2.80)$ which indicates the poorer quality of life in the caregiver of alcohol dependent patient. Conclusion: The study concluded that burden level on the primary caregiver of alcohol dependent patient was moderate to severe. The quality of life of the caregiver of alcohol dependent patient had poorer quality of life.
\end{abstract}

Keywords: Alcoholism, Caregivers, International Classification of Diseases, Nepal, Quality of Life

\section{Introduction}

In most families, members who provide care for the patients of alcohol dependence syndrome are affected tremendously. Caregivers suffer issues like family conflicts, economic crisis and abuse in the hands of the patients resulting in losing meaning of their lives and experiencing hopelessness [1]. Alcohol Dependence is considered a "family disease" because alcohol dependence affects the individual and those around them in terms of occupational and social dysfunction, physical and emotional distress and financial problems which has a major effects on the lives of significant others [2].

Family plays an important role in the care of patient with mental illness [3]. This is true in Nepal because of factors like tradition of interdependence. In many countries, alcohol dependence has been a major social and personal trouble. As per Global Status Report on alcohol, Alcohol Use Disorder (AUD) account for $1.4 \%$ of the global disease burden [4]. 
Caregiver is the person who would do the physical and psychological needs of the dependent patient [5]. It is the caregiver's perception of burden that decides the influence on his or her life [6].

Caregiver burden is conceptualized as the work that can be done in the course of caregiving and the way in which the caregiver values the performance of these work [7]. Factors like caregiver's personality, social support network, status in the family and other responsibilities effects how a person value their caregiving responsibilities [8, 9]. Many literatures have concluded that caregivers with strong social support report less burden than who lack social support [10-12] regardless of the number or type of care giving tasks [7].

Caregiver burden has been defined as the type of stress or strain that they experience related to the problems and challenges they face as a result of the status of the care recipient. It is the condition arising from necessary caring tasks or restrictions that cause discomfort for the caregiver [13]. Caregiver burden affects the physical, psychological, emotional and functional health of caregivers [14]. Caregiver often suffers depression, develop maladaptive coping strategies and express concern about their quality of life [15-17].

Caregiver burden can be both observable and perceived. Objective burden is one that is observed, concrete, actual, price that charge to the caregiver for taking care of the recipient. Subjective burden is the feeling or experience perceived such as how much the caregiver is worry by performing these tasks and the positive and negative feeling while caregiving [18]. Hoeing and Hamilton in 1966 mentioned objective burden as the influence of the disease on earnings and activities of the family and subjective burden as degree to which family members are influenced by the objective burden [19].

A study from India comparing the family burden of patients with schizophrenia, alcohol dependence, and opioid dependence by using the Family Burden Interview Schedule (FBIS) showed moderate to severe burden in all the three groups [20].

According to WHO, the quality of life of an individual is the understanding of their position in life within the context of the culture and values system where they live and in reference to their goals, expectations, standards and concerns [21]. The quality of life is the person's perceptions of physical, psychological and social domains of health which is defined by personal experiences, faith, hopes and concepts [22-24]. Quality of life measurement assesses differences in physical, functional, mental and social health in respect to human and financial costs and benefits [25].

Quality of life model is the objective and subjective evaluation, which shows a wider range of life domains, through an individual hierarchical judgment of the relative importance of each domain. Although individual can burden to certain conditions as less meaningful than others, the objective assessment of those burden is still a part of the total assessment and can be compared to those typically suffered [26].

Substance use, abuse and dependence attribute considerable suffering to the individual, family members and community in overall [27]. Family and nation has to pay the enormous expenditure because of the substance use. These comprise open and hidden expenditure. Also it can hinder with individual profession and performance. In a study $59.4 \%$ of families were financed by other family members and $9.7 \%$ children under 15 years for earnings to support family [28]. Mainly in the family, wives have greater threat of distressful life happenings, medical and psychiatric illness and increase use of medical attention [29-33].

Burden and quality of life of the caregiver of patients with alcohol dependence syndrome is neglected area in the psychiatric research. There are limited studies regarding impact of the alcohol dependence patients on the primary caregiver in Nepal. The objective of this study was to study the burden and quality of life among primary caregiver of alcohol dependence syndrome.

\section{Material and Method}

This was a hospital based cross-sectional study conducted at the outpatient and inpatient unit of the Department of Psychiatry, National Medical College and Teaching Hospital, Birgunj, Parsa, Nepal after obtaining approval from Institutional Review Committee (IRC-NMC). The target population were the primary caregiver of patient who stayed for most of the time of the patient's illness, taking care of the patient with alcohol dependence syndrome. Total numbers of patients enrolled in this study were 123. All the patients of alcohol dependence syndrome meeting the inclusion criteria of this study over the period of one year were included in this study. A non-probability homogeneous purposive sampling, a type of non-random sampling technique was used for this study. The study duration was of 1 year from July 2018 to June 2019.

The inclusion criteria for the study was age group of the patients and caregiver between 20 to 60 years, the primary caregiver who stayed with patient of alcohol dependence syndrome for minimum of one year duration and given consent to participate in this study. The exclusion criteria are the primary caregiver who is the known case of mental illness and are dependent on alcohol or any substances.

The socio-demographic profile of alcohol dependence patients and their primary caregivers were assessed using semi-structured proforma.

The burden was assesses with the help of Family Burden Interview Schedule (FBIS). FBIS was developed by Pai and Kapoor (1981) and it measures the burden perceived by caregivers caring for patients with mental illness [34]. The reliability of FBIS is 0.87 and validity is 0.72 . The average time taken for administration would be 15 minutes [34].

The quality of life was assessed with the help of World Health Organization Quality of Life (WHOQOL) BREF version [21]. The WHOQOL is a quality of life assessment developed by the WHOQOL Group with 15 the international field centers, simultaneously, in an attempt to develop a quality of life assessment that would be applicable cross- 
culturally. Quality of life (QOL) assessments that are easily administered and which do not impose a great burden on the respondent are needed for use in large epidemiological surveys, clinical settings and clinical trials [21].

The data was entered and analyzed using SPSS 21.

\section{Result}

Table 1. Socio-demographic characteristics of the patients.

\begin{tabular}{|c|c|c|}
\hline Variables & Frequency & Percentage \\
\hline \multicolumn{3}{|l|}{ Patient's age (in years) } \\
\hline $20-30$ & 5 & $4.1 \%$ \\
\hline $31-40$ & 53 & $43.1 \%$ \\
\hline $41-50$ & 44 & $35.8 \%$ \\
\hline $51-60$ & 21 & $17.1 \%$ \\
\hline \multicolumn{3}{|l|}{ Gender } \\
\hline Male & 122 & $99.2 \%$ \\
\hline Female & 1 & $0.8 \%$ \\
\hline \multicolumn{3}{|l|}{ Marital Status } \\
\hline Married & 121 & $98.4 \%$ \\
\hline Unmarried & - & - \\
\hline Divorced & 1 & $0.8 \%$ \\
\hline Widowed & 1 & $0.8 \%$ \\
\hline \multicolumn{3}{|l|}{ Religion } \\
\hline Hindu & 108 & $87.8 \%$ \\
\hline Muslim & 10 & $8.1 \%$ \\
\hline Buddhist & 5 & $4.1 \%$ \\
\hline Other & - & - \\
\hline \multicolumn{3}{|l|}{ Family type } \\
\hline Nuclear & 102 & $82.9 \%$ \\
\hline Joint & 6 & $4.9 \%$ \\
\hline Extended & 15 & $12.2 \%$ \\
\hline \multicolumn{3}{|l|}{ Education } \\
\hline Illiterate & 20 & $16.3 \%$ \\
\hline Primary school/Just literate & 37 & $30.1 \%$ \\
\hline Middle school certificate & 53 & $43.1 \%$ \\
\hline High school certificate & 8 & $6.5 \%$ \\
\hline \multicolumn{3}{|l|}{ Intermediate of post high school } \\
\hline diploma & 3 & $2.4 \%$ \\
\hline Graduate/Post-graduate & 2 & $1.6 \%$ \\
\hline Professional/Honors & - & - \\
\hline \multicolumn{3}{|l|}{ Locality } \\
\hline Urban & 23 & $18.7 \%$ \\
\hline Rural & 100 & $81.3 \%$ \\
\hline
\end{tabular}

Mean age (in years) of the patients $=42.80 \pm 7.88$

Table 1 shows the distribution of the patient's demographic profile. On age wise distribution, the majority were in the range of 31-40 years age groups accounting for $43.1 \%$. The lowest age groups of the patients were in the range of 20-30 years age groups accounting for $4.1 \%$. On gender wise distribution of the patients, the majority of the patients were male accounting for $99.2 \%$ and only $0.8 \%$ was female. On marital status distribution, majority of the patient's were married accounting for $98.4 \%$ and divorced and widowed were only $0.8 \%$ each. On religion wise distribution, majority of the patients were Hindu accounting for $87.8 \%$. Most of the family types were nuclear accounting for the $82.9 \%$ followed by extended accounting $12.2 \%$ and joint accounting for $4.9 \%$. On education wise distribution, majority of the patient's had passed middle school certificate accounting for $43.1 \%$. Majority of the patient belong from rural background accounting for $81.3 \%$.

Table 2. Socio-demographic characteristics of the care givers.

\begin{tabular}{|c|c|c|}
\hline Variables & Frequency & Percentage \\
\hline \multicolumn{3}{|l|}{ Caregiver's age (in years) } \\
\hline $20-30$ & 15 & $12.2 \%$ \\
\hline $31-40$ & 63 & $51.2 \%$ \\
\hline $41-50$ & 35 & $28.5 \%$ \\
\hline $51-60$ & 10 & $8.1 \%$ \\
\hline \multicolumn{3}{|l|}{ Gender } \\
\hline Male & 6 & $4.9 \%$ \\
\hline Female & 117 & $95.1 \%$ \\
\hline \multicolumn{3}{|l|}{ Marital Status } \\
\hline Married & 121 & $98.4 \%$ \\
\hline Unmarried & 2 & $1.6 \%$ \\
\hline Divorced & - & - \\
\hline Widowed & - & - \\
\hline \multicolumn{3}{|l|}{ Education } \\
\hline Illiterate & 65 & $52.8 \%$ \\
\hline Primary school/ Just literate & 34 & $27.6 \%$ \\
\hline Middle school certificate & 15 & $12.2 \%$ \\
\hline High school certificate & 6 & $4.9 \%$ \\
\hline Intermediate of post high school diploma & 1 & $0.8 \%$ \\
\hline Graduate/Post graduate & 2 & $1.6 \%$ \\
\hline Professionals/ Honors & - & - \\
\hline \multicolumn{3}{|l|}{ Occupation } \\
\hline Homemaker & 96 & $78 \%$ \\
\hline Unskilled worker & 10 & $8.1 \%$ \\
\hline Semi-skilled worker & 7 & $5.7 \%$ \\
\hline Skilled worker & 2 & $1.6 \%$ \\
\hline Clerical, Shop owner, Farmer & 2 & $1.6 \%$ \\
\hline Semi-Professional & 1 & $0.8 \%$ \\
\hline Professional & 5 & $4.1 \%$ \\
\hline
\end{tabular}

Mean age (in years) of the caregivers $=39.06 \pm 7.78$

Table 2 shows the distribution of the primary caregiver demographic profile. On age wise distribution of the caregiver, the majority were in the range of 31-40 years age groups accounting for $51.2 \%$. The lowest age groups of the caregiver were in the range of 51-60 years age groups accounting for $8.1 \%$. On gender wise distribution the majority was female accounting for $95.1 \%$. On marital status distribution, majority of the caregiver were married accounting for $98.4 \%$, only $1.6 \%$ were not married and none of the caregiver were divorced or widowed. On education wise distribution, the majority of the caregivers of were illiterate accounting for $52.8 \%$. On occupation wise distribution, majority of the caregiver's were homemakers accounting for $78 \%$.

The table 3 shows findings on Family Burden Interview Schedule of the primary caregiver of Alcohol Dependence patient. On financial burden domain, $61.6 \%$ experienced moderate level of burden followed by $32.8 \%$ experiencing severe level of burden. On disruption of routine family activities domain, $69.1 \%$ of the caregiver experiencing moderate level of burden followed by $27.6 \%$ experiencing severe level of burden. On disruption of family leisure domain, $83.7 \%$ of the caregiver experienced the moderate level of burden. On disruption of family interaction domain, $81.3 \%$ experienced moderate level of burden and $13.8 \%$ experiences severe level of burden. $91.9 \%$ of the samples 
experienced no burden on the effect of physical health of other domain. On effect on mental health of other domain, the highest percentage $(65.9 \%)$ experienced the moderate level of burden and $30.9 \%$ experienced the severe level of burden. On subjective burden domain, the maximum respondents experienced the moderate level of burden.

Table 3. Distribution of severity of burden to the caregiver according to the FBIS.

\begin{tabular}{lll}
\hline Variables & Frequency & Percentage \\
\hline Financial burden & & \\
No burden & - & - \\
Moderate burden & 76 & $61.6 \%$ \\
Severe burden & 47 & $38.2 \%$ \\
Disruption of routine family activities & & \\
No burden & 4 & $3.3 \%$ \\
Moderate burden & 85 & $69.1 \%$ \\
Severe burden & 34 & $27.6 \%$ \\
Disruption of family leisure & & \\
No burden & 4 & $3.3 \%$ \\
Moderate burden & 103 & $83.7 \%$ \\
Severe burden & 16 & $13 \%$ \\
Disruption of family interaction & & \\
No burden & 6 & $4.9 \%$ \\
Moderate burden & 100 & $81.3 \%$ \\
Severe burden & 17 & $13.8 \%$ \\
Effect on physical health of others & & \\
No burden & 113 & $91.9 \%$ \\
Moderate burden & 8 & $6.5 \%$ \\
Severe burden & 2 & $1.6 \%$ \\
Effect on mental health of others & & $3.3 \%$ \\
No burden & 4 & $65.9 \%$ \\
Moderate burden & 81 & $30.9 \%$ \\
Severe burden & 38 & \\
Subjective burden & 5 & $10.6 \%$ \\
No burden & $5.1 \%$ \\
Moderate burden & & \\
Severe burden & & \\
\hline
\end{tabular}

Table 4. WHOQOL-BREF of the caregivers.

\begin{tabular}{lll}
\hline WHOQOL-BREF & Mean & Standard Deviation \\
\hline Over all perception of QOL & 2.78 & \pm 0.66 \\
Over all perception of their health & 3.57 & \pm 0.64 \\
Physical health & 23.40 & \pm 3.04 \\
Psychological health & 18.91 & \pm 2.36 \\
Social relationships & 10.63 & \pm 1.39 \\
Environmental & 25.58 & \pm 2.80 \\
\hline
\end{tabular}

The table 4 shows the mean and standard deviation of the different domains of the WHOQOL-BREF. On the overall perception of quality of life, the mean was $2.78( \pm 0.66)$ and the mean of the overall perception of their health was 3.57 $( \pm 0.64)$. Similarly, the mean $( \pm \mathrm{SD})$ for the physical health, psychological health, social relationships and environmental was $23.40( \pm 3.04), 18.91( \pm 2.36), 10.63( \pm 1.39)$ and 25.58 $( \pm 2.80)$ respectively.

\section{Discussion}

This study is tertiary hospital based study. It was conducted among primary caregivers of patients suffering from Alcohol Dependence Syndrome.

The majority of patients $(43.1 \%)$ belonged to the $31-40$ years of age in this study. The $51.2 \%$ of the primary caregivers belonged to the same age group. These finding were similar to the previous study from India [35]. As per the general trend in this region, the younger patients are usually taken to rehabilitation centers and older patients are often neglected in family and society. This is the possible reason behind the samples of 31-40 years in this study. The older patients with alcohol dependence are also likely to have medical co-morbidities, who are often seen by physicians in this region. The mean age of the patients of alcohol dependence in current study was same as the previous study $[35,36]$. This was present because of socio cultural similarities between Nepal and India.

Most of the primary caregivers were female (95.1\%) which was comparable to previous study [37]. Mostly men work for the earnings in this culture and females stay in as homemaker. The majority of patients were male (99.2\%) which is similar to the previous study [38]. Males are the primary worker of the family and are likely to take alcohol for different purposes like relaxation after work, recreation and for sleep. [39] Almost all patients were married (98.4\%). This study had similar socio-demographic profile with the early study from Nepal [30].

This study differs from earlier study [40] in terms of education and occupation of the primary caregiver. More than half of the primary caregivers were illiterate $(52.8 \%)$ and homemakers $(78 \%)$. As most of the caregivers were females and illiterate, it can be said that literacy in females is low in this region.

Religion was comparable to the previous study [37]. People mostly followed Hinduism in Nepal that ranked highest in our study. Geographically, Muslims are mostly populated in Terai region and so they were second highest.

Further, most of the patients $(81.3 \%)$ were from rural background in this study. Generally, people from the rural population are financially weak and the medical college provides cheaper treatment to them. So, they tend to visit here. However, urban and affording population goes to either private hospitals or rehabilitation centers in town where the treatment is costly. In addition, the study center is only one tertiary care providing service with psychological intervention. So the patients from nearby villages come here for treatment.

In this study, moderate to severe burden was observed on each of the Family Burden Interview Schedule (FBIS) scale except the effect on physical health of other. The earlier studies were comparable with this finding [36, 37]. The possible assumptions for primary caregiver burden could be as follows: wife being financially dependent on the husband, responsibility of upbringing children, illiteracy and lack of occupational skills. One of the most important reasons is the social isolation following separation from husband.

The study found that maximum moderate burden was due to the disruption of family leisure. The possible reason could be following:

i) If a person in family gets sick, the primary caregiver has to look after him/her. Generally one cannot go 
outside for personal leisure or relaxation.

ii) At times, primary caregiver has to take leave to look after patient in hospital or at home where their personal leisure is lost.

iii) When a person at home is sick, the primary caregiver might not have adequate time to look for their children necessities.

The study also found $91.9 \%$ of the primary caregivers had no burden on the physical health of others which is similar to the previous study [36]. The possible reason could be that behavior of the patients does not directly involve the physical health of primary caregiver. However, this may not apply when the patient is violent. Other reason could be that the primary caregivers are mainly psychologically and emotionally attached to the patients. The primary caregiver could not leave the patient alone because there are very few centers for proper care of patients' rehabilitation and long term treatment. There are some rehabilitation centers in this city that are not only costly but also lack psychiatric supervision. This ultimately increases the likelihood of relapse that increases the burden on the family and the caregiver.

The present study found the caregivers quality of life is most affected in social domain followed by psychological, physical and environmental. These findings were found to be comparable with the findings of earlier study [41]. The possible assumptions could be:

i) Social stigma about alcoholic patient and to their family

ii) Social relation of the family member might not be good as others because of the behavior of patient in the society.

iii) People might not get ready to help instantly to their family.

There are few limitations of this study. The sample size was relatively small and this study was conducted only in the tertiary care hospital because of which it may lack extrapolation to the community at large. Therefore, it cannot be generalized. Also, as it was a cross sectional study, it lacks follow-up for future outcomes. The next limitation is that there was no comparison between control group and the primary caregiver of Alcohol dependence in this study. Therefore, the factors of the burden and the quality of life could not be measured.

\section{Conclusion}

This study demonstrated socio-demographic profiles of the alcohol dependent patients and their primary caregivers, along with the various burden and quality of life of the caregiver of the alcohol dependent patient. The study concludes that burden level on the primary caregiver was moderate to severe. The social domain of quality of life of the caregiver was poor. Therefore, it is necessary to evaluate the burden and quality of life of caregiver so that a clinician can provide needed psychosocial, clinical and psychological support.

From the clinical point of view, we should go beyond the treatment i.e. preventing relapses, evaluate the primary caregiver and do necessary intervention. This will ultimately improve the quality of family along with the better caring for the patient of alcohol dependence.

\section{References}

[1] Gohil JG, Patel MK, Samani MJ. Quality of life and psychiatric morbidity in caregiver of alcohol dependence patients. IOSR Journal of Dental and Medical Sciences. 2016; 15 (08): 98-101.

[2] Platt S. Measuring the burden of psychiatric illness on the family: an evaluation of some rating scales. Psychol Med. $1985 ; 15$ (2): 383-93

[3] Avasthi A. Preserve and strengthen family to promote mental health. Indian J Psychiatry. 2010; 52 (2): 113-26.

[4] World Health Organization, Department of Mental Health and Substance Abuse. Global Status Report on Alcohol 2004. World Health Organization, Geneva; 2004.

[5] Ampalam P, Gunturu S, Padma V. A comparative study of caregiver burden in psychiatric illness and chronic medical illness. Indian J Psychiatry. 2012; 54 (3): 239-43.

[6] Kasuya RT, Polgar-Bailey P, Takeuchi R. Caregiver burden and burnout a guide for primary care physicians. Postgrad Med. 2000; 108 (7): 119-23.

[7] Rospenda KM, Minich LM, Milner LA, Richman JA. Caregiver burden and alcohol use in a community sample. J Addict Dis. 2010; 29 (3): 314-24.

[8] Chenier MC. Review and analysis of caregiver burden and nursing home placement: the multiple problems and variables affecting the caregiving relationships require multiple approaches and interventions. Geriatric Nursing. 1997; 18 (3): 121-6.

[9] Lawton MP, Kleban MH, Moss M, Rovine M, Glicksman A. Measuring caregiving appraisal. J Gerontol. 1989; 44 (3): 61-71.

[10] Goodman CC, Potts MK, Pasztor EM. Caregiving grandmothers with vs. without child welfare system involvement: Effects of expressed need, formal services, and informal social support on caregiver burden. Children and Youth Services Review. 2007; 29 (4): 428-41.

[11] Miller B, Townsend A, Carpenter E, Montgomery RV, Stull D, Young RF. Social support and caregiver distress: A replication analysis. J Gerontol B Psychol Sci Soc Sci. 2001; 56 (4): S249-56.

[12] Vrabec NJ. Literature review of social support and caregiver burden, 1980 to 1995. Image: The Journal of Nursing Scholarship. 1997; 29 (4): 383-8.

[13] Zarit SH, Reever KE, Bach-Peterson J. Relatives of the impaired elderly: correlates of feelings of burden. Gerontologist. 1980; 20 (6): 649-55.

[14] Carretero S GJ, Rodenas F, SanjoseV. The informal caregiver's burden of dependent people: Theory and empirical review. Arch Gerontol Geriatr. 2009; 49 (1): 74-9. 
[15] Serrano-Aguilar PG, Lopez-Bastida J, Yanes-Lopez V. Impact on health-related quality of life and perceived burden of informal caregivers of individuals with Alzheimer's disease. Neuroepidemiology. 2006; 27 (3): 136-42.

[16] Papastavrou E, Kalokerinou A, Papacostas SS, Tsangari H, Sourtzi P. Caring for a relative with dementia: family caregiver burden. J Adv Nurs. 2007; 58 (5): 446-57.

[17] Molyneux GJ, McCarthy GM, McEniff S, Cryan M, Conroy RM. Prevalence and predictors of carer burden and depression in carers of patients referred to an old age psychiatric service. Int Psychogeriatrics. 2008; 20 (6): 1193-202.

[18] Jones SL. The association between objective and subjective caregiver burden. Arch Psychiatr Nurs. 1996; 10 (2): 77-84.

[19] Hoenig J, Hamilton MW. The schizophrenic patient in the community and his effect on the household. Int J Social Psychiatry. 1966; 12 (3): 165-76.

[20] Chandra K. Burden and coping in caregivers of men with alcohol and opioid dependence: MD dissertation. Chandigarh, India: Postgraduate Institute of Medical Education \& Research-2004. 2004.

[21] Program on Mental Health World Health Organization. WHOQOL-BREF: introduction, administration, scoring and generic version of the assessment: field trial version, December 1996. World Health Organization, Geneva: 1996.

[22] Brook RH, Ware JE, Davies-Avery A, Stewart AL, Donald $\mathrm{CA}$, Rogers $\mathrm{WH}$, et al. Overview of adult health measures fielded in Rand's health insurance study. Med Care. 1979; 19 (7 Suppl): iii-x, 1-131.

[23] Patrick DL, Bush JW, Chen MM. Toward an operational definition of health. J Health Soc Behav. 1973; 14 (1): 6-23.

[24] Brook RH, Ware Jr JE, Rogers WH, Keeler EB, Davies AR, Donald CA, et al. Does free care improve adults' health? Results from a randomized controlled trial. N Engl J Med. 1983; 309 (23): 1426-34.

[25] Testa MA, Simonson DC. Assessment of quality-of-life outcomes. N Engl J Med. 1996; 334 (13): 835-40.

[26] Felce D, Perry J. Quality of life: Its definition and measurement. Res Dev Disabil. 1995; 16 (1): 51-74.

[27] Shyangwa PM, Tripathi BM, Lal R. Family burden in opioid dependence syndrome in tertiary care centre. JNMA J Nepal Med Assoc. 2008; 47 (171): 113-9.

[28] Benegal V, Velayudhan A, Jain S. Social cost of alcoholism: A Karnataka perspective. NIMHANS Journal. 2000; 18 (1\&2): 67-76.
[29] Lennox RD, Scott-Lennox JA, Holder HD. Substance abuse and family illness: Evidence from health care utilization and cost-offset research. J Ment Health Adm. 1992; 19 (1): 83-95.

[30] Holder HD. The cost offsets of alcoholism treatment. Recent developments in alcoholism: Springer; 1998. p. 361-74.

[31] Connors GJ, DiClemente CC, Velasquez MM, Donovan DM. Substance abuse treatment and the stages of change: Selecting and planning interventions. Second Edition. Guilford Press: 2015.

[32] Bhowmick P, Tripathi BM, Jhingan HP, Pandey RM. Social support, coping resources and codependence in spouses of individuals with alcohol and drug dependence. Indian J Psychiatry. 2001; 43 (3): 219-24.

[33] Ray GT, Mertens JR, Weisner C. The excess medical cost and health problems of family members of persons diagnosed with alcohol or drug problems. Med Care. 2007; 45 (2): 116-22.

[34] Pai S, Kapur RL. The burden on the family of a psychiatric patient: development of an interview schedule. Br J Psychiatry. 1981; 138: 332-5.

[35] Murali Krishna V, Tialam G, Macharapu R. Duration, onset, severity of alcohol dependence in patients and its relation to quality of life of their caregivers. MedPulse- International Journal of Psychology. 2017: 4 (2): 32-8.

[36] Mattoo SK, Nebhinani N, Kumar BNA, Basu D, Kulhara P. Family burden with substance dependence: a study from India. Indian J Med Res. 137 (4): 704-11.

[37] Vaishnavi R, Karthik MS, Balakrishnan R, Sathianathan R. Caregiver burden in alcohol dependence syndrome. J Addict. 2017; 2017: 8934712.

[38] Gautam SC, Bhattarai Y. Spouse Burden in Patients with Alcohol Dependence Syndrome. Nepal Journal of Neuroscience. 2019; 16 (3): 27-33.

[39] Lamichhane N, Shyangwa PM, Shakya R. Family burden in substance dependence syndromes. Journal of Gandaki Medical College-Nepal. 2008; 1: 53-61.

[40] Kishor M, Pandit LV, Raguram R. Psychiatric morbidity and marital satisfaction among spouses of men with alcohol dependence. Indian J Psychiatry. 2013; 55 (4): 360-5.

[41] Ganesh S, Bhat SM, Latha KS. Burden and Quality of Life among Care Givers of Persons with Alcohol Dependence Syndrome - A Hospital based Interventional Study. IOSR Journal of Humanities And Social Science (IOSR-JHSS). 2017; 22 (12): 20-8. 